\title{
Hemorrhagic Posterior Reversible Encephalopathy Syndrome as a Manifestation of COVID-19 Infection
}

\author{
(D) A.M. Franceschi, (D) O. Ahmed, (D). Giliberto, and (D) M. Castillo
}

\section{ABSTRACT}

SUMMARY: We describe 2 hospitalized patients with confirmed coronavirus 19 (COVID-19) infection in whom brain imaging showed hemorrhagic posterior reversible encephalopathy syndrome, and we discuss the possible reasons for these findings and their relationship to the infection.

ABBREVIATIONS: ACE2 = angiotensin-converting enzyme 2; COVID-19 = coronavirus 19; PRES = posterior reversible encephalopathy syndrome; SARS-CoV$2=$ Severe Acute Respiratory Syndrome coronavirus 2

$\mathbf{T}$ he current pandemic of Severe Acute Respiratory Syndrome coronavirus 2 (SARS-CoV-2) coronavirus 19 (COVID-19) has, to date, infected nearly 2 million people worldwide, resulting in $>120,000$ deaths as of mid-April 2020, spreading across continents with cases reported in 213 countries and territories. ${ }^{1}$ Thus far, the scientific literature in terms of diagnosis and therapeutics has primarily focused on the respiratory status of affected individuals. ${ }^{2}$ Neurologic manifestations are becoming increasingly recognized ${ }^{3-5}$ and have been described in 78 of 214 (36.4\%) patients in a study of patients with severe and nonsevere conditions who are positive for COVID-19. The findings can be, in part, attributed to the affinity of SARS-CoV-2 coronavirus for the angiotensin-converting enzyme 2 (ACE2) receptor, which is a relatively common functional receptor in both the respiratory and nervous systems. In fact, in some patients, neurologic symptoms preceded respiratory illness by several days or were the only indicators of disease in otherwise asymptomatic COVID-19 carriers. ${ }^{5}$ Postmortem data have demonstrated hyperemic and edematous brain parenchyma with associated neuronal degeneration in early postmortem studies of patients with SARS-CoV-2, ${ }^{6}$ and similar neurologic manifestations have been reported in related coronavirus infections such as SARS and Middle East Respiratory Syndrome. ${ }^{7,8}$

Received April 18, 2020; accepted after revision April 24.

From the Neuroradiology Section, Department of Radiology (A.M.F.) and Department of Neurology (L.G.), Donald and Barbara Zucker School of Medicine at Hofstra/Northwell Health, Manhasset, New York; Department of Radiology (O.A.), Stony Brook University Hospital, Stony Brook, New York; and Neuroradiology Section, Department of Radiology (M.C.), University of North Carolina School of Medicine, Chapel Hill, North Carolina.

Please address correspondence to Ana M. Franceschi, MD, Department of Radiology, 300 Community Dr, Manhasset, NY, 11030-3816;

e-mail: afranceschi@northwell.edu

- Indicates open access to non-subscribers at www.ajnr.org

http://dx.doi.org/10.3174/ajnr.A6595

\section{Case Reports}

Patient 1. A 48-year-old male airline pilot was exposed to COVID-19 on March 12, 2020, and then self-quarantined. With the exception of obesity, the patient had no pertinent medical or surgical history and was not on any medications.

He subsequently developed fever and cough on March 17, had polymerase chain reaction testing positive for SARS-CoV-2, and was admitted into a local hospital for medical care. Two days later, the fever progressed to $105^{\circ} \mathrm{F}$ and he developed difficulty breathing and was transferred to a tertiary medical center for intensive care unit care and was placed on mechanical ventilation. On March 25, he developed shock with widely varying blood pressures from 70/30 to $180 / 90 \mathrm{~mm} \mathrm{Hg}$ during his intensive care stay. On April 4, he was diagnosed with inflammatory cytokine release syndrome (high D-dimer, lactate dehydrogenase, C-reactive protein, and ferritin values) and developed an altered mental status. Noncontrast CT of the head was obtained and demonstrated focal vasogenic/cytotoxic edema in the posterior parietooccipital regions bilaterally, which was subcortical in distribution, with a small right-sided hemorrhage (Fig 1); concurrently obtained CT venogram findings were normal. The patient was extubated and transferred to a medical floor on April 10, with gradual improvement in his mental status. MR imaging of the brain was performed on April 13 and confirmed vasogenic edema in the posterior parieto-occipital regions with subacute blood products suggestive of hemorrhagic posterior reversible encephalopathy syndrome (PRES). SWI revealed extensive petechial hemorrhages diffusely distributed throughout the corpus callosum (Fig 2).

Patient 2. A 67-year-old woman with multiple comorbidities and past medical history of hypertension, diabetes, coronary 


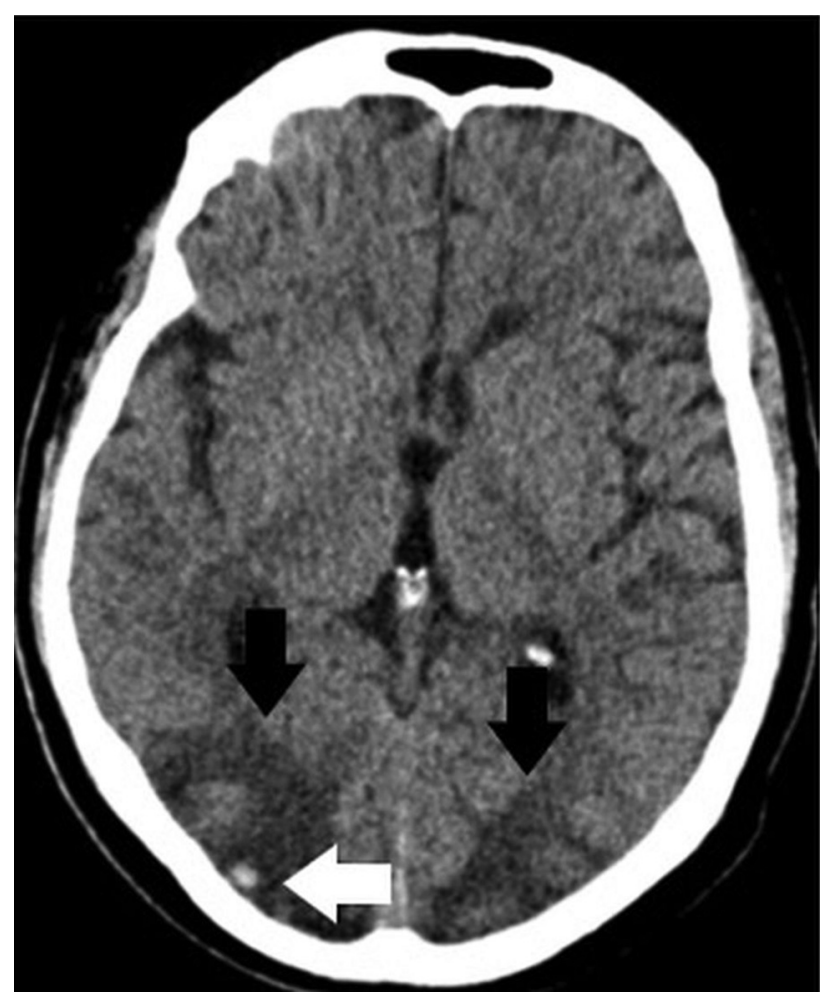

FIG 1. Axial noncontrast CT demonstrates edema in the posterior parieto-occipital regions (black arrows) with a superimposed small right-side hemorrhage (white arrow). artery disease, gout, and asthma resided in a local rehabilitation and skilled nursing center affected by the COVID-19 outbreak.

On March 25, she developed altered mental status, including lethargy and confusion, and was transferred to our hospital. In the emergency department, the patient was afebrile, with laboratory values notable for $\mathrm{Cr}=1.65$, blood urea nitrogen $=23$, lactate $=$ 2.3, and mild hyponatremia. Arterial blood gases were normal, and she denied cough, chest pain, and shortness of breath. The patient had variations in blood pressure, ranging from 115/72 to $178 / 83$ $\mathrm{mm} \mathrm{Hg}$ at admission. Chest CT demonstrated bilateral multifocal ground-glass opacities concerning for COVID-19 pneumonia due to its high prevalence in the region. Findings of a polymerase chain reaction test were positive for SARS-CoV-2 on March 27. Noncontrast head CT demonstrated edema in the bilateral parietooccipital regions with associated mass effect and cortical sulcal effacement (Fig 3). MR imaging of the brain performed on March 27 revealed multiple areas of restricted diffusion with associated edema, most extensive in the posterior parieto-occipital lobes but also in the right frontal lobe, basal ganglia, and cerebellar hemispheres. The SWI sequence demonstrated extensive superimposed hemorrhages in the parieto-occipital region along with abnormal enhancement (Fig 4). Findings of concurrently performed MR angiography of the head and neck were unremarkable: Specifically, evaluation of the posterior circulation demonstrated a patent vertebrobasilar system. The patient remained afebrile with normal respiratory status, including oxygen saturation; after gradual improvement in her mental status, she was discharged.
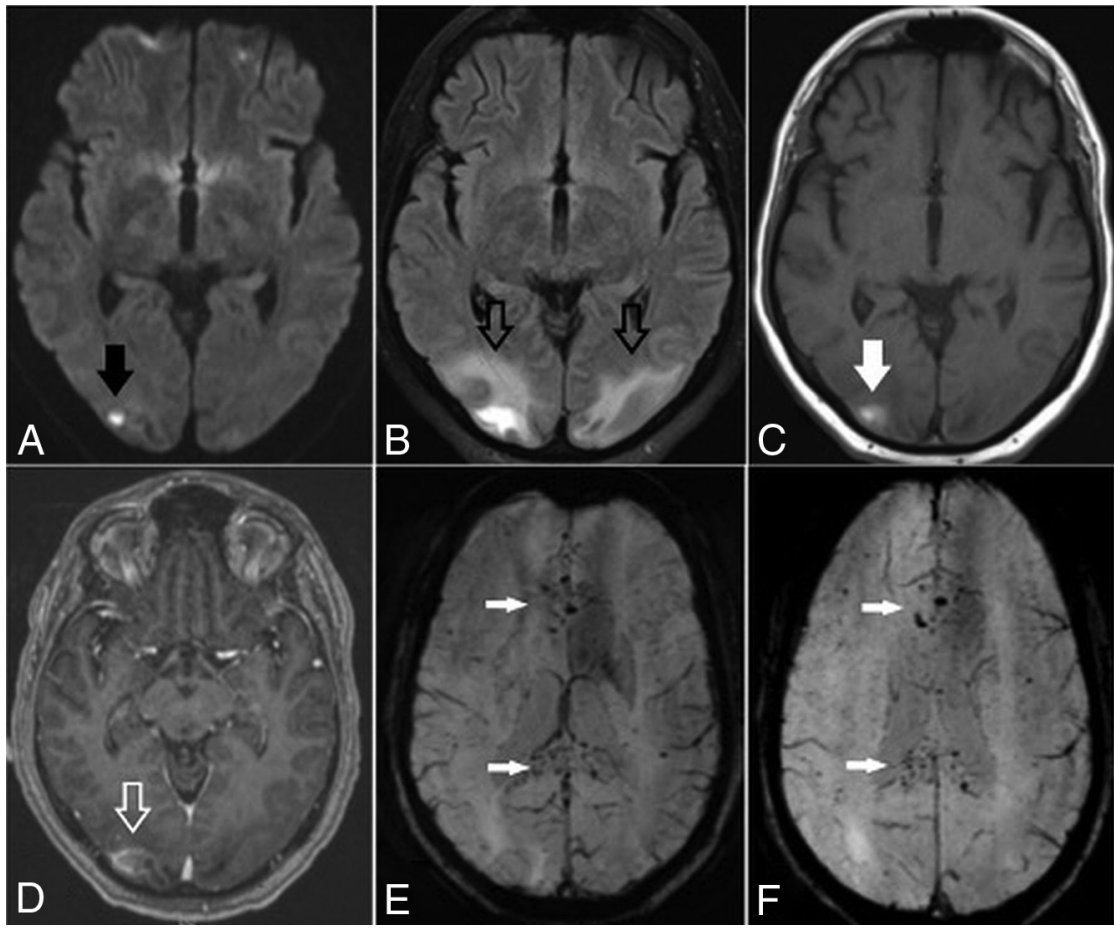

FIG 2. Brain axial DWI (A), FLAIR (B), precontrast T1-weighted (C), postcontrast T7-weighted (D), and susceptibility-weighted ( $E$ and $F$ ) images obtained 8 days after $C T$ demonstrate a small infarct in the right occipital region (arrow, $A$ ), persistent edema in the posterior parieto-occipital regions (hollow black arrows, B), subacute blood products in the location of the infarction (solid white arrow, C), and some contrast enhancement (hollow white arrow, D). There are diffuse petechial hemorrhages on SWI throughout the corpus callosum (white arrows, $E$ and $F$ ).

\section{DISCUSSION}

PRES is a well-described phenomenon presenting clinically as an acute neurologic syndrome with headache, altered mental status, seizures, and/or visual disturbances and accompanied by fluctuations in blood pressure. ${ }^{9}$ It is associated with conditions such as eclampsia and preeclampsia and various autoimmune and rheumatologic disorders, in the setting of cytotoxic and immunosuppressive treatments. The underlying pathophysiologic mechanism of PRES remains controversial but is commonly attributed to alterations in the integrity of the BBB, possibly due to loss of autoregulation and/or endothelial dysfunction. Dominant imaging features of PRES include vasogenic edema predominantly in the parieto-occipital lobes, though abnormalities may also be seen in the watershed distributions, frontal lobes, inferior temporal lobes, basal ganglia, brain stem, and cerebellum. Furthermore, reports have described hemorrhagic complications of PRES in 15\%-20\% of cases, including both petechial hemorrhages 


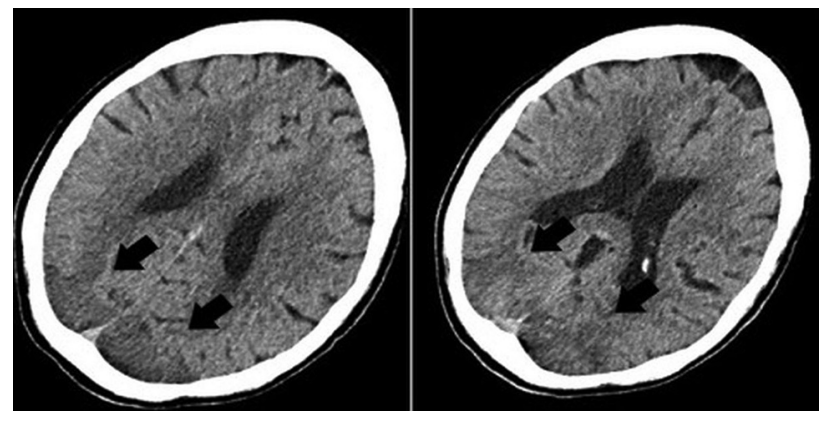

FIG 3. Axial noncontrast $C T$ images demonstrate vasogenic/cytotoxic edema in the parieto-occipital regions suggestive of PRES (arrows).

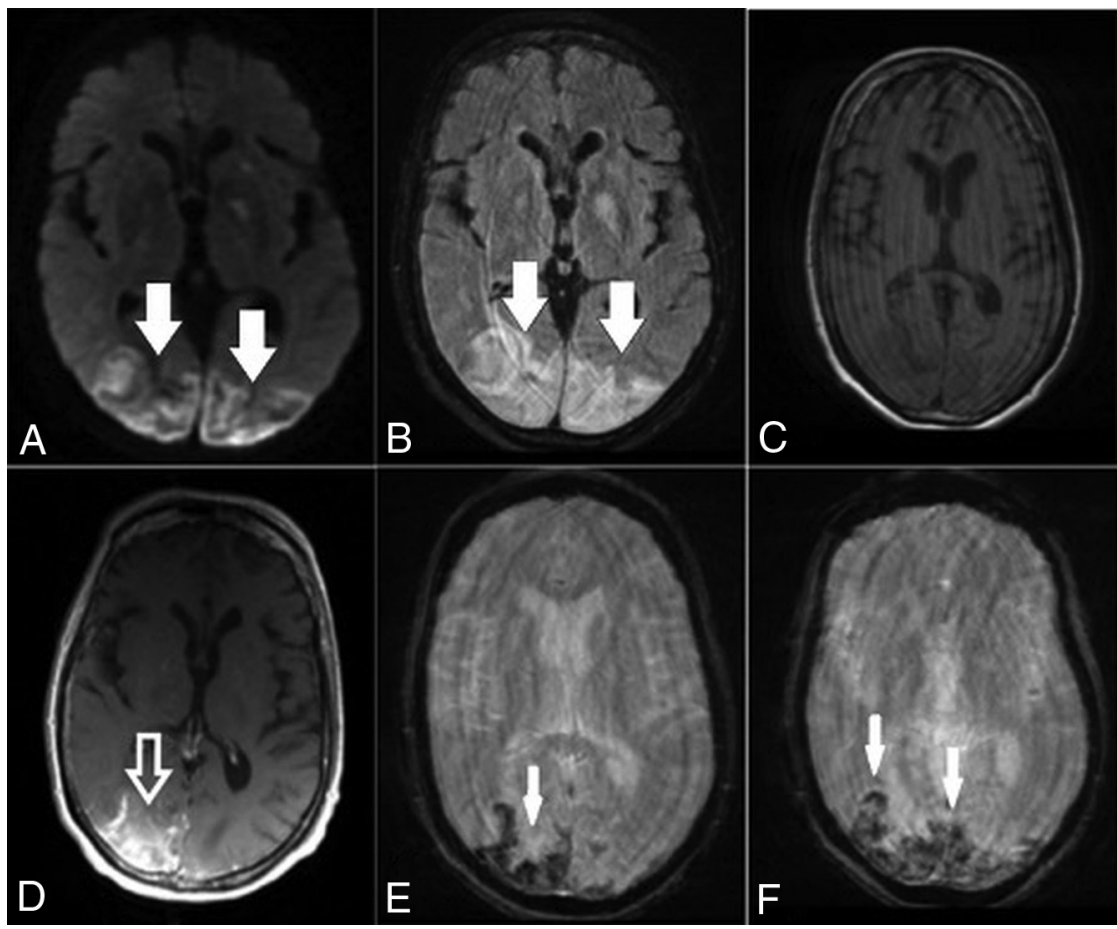

FIG 4. Brain axial DWI $(A)$, FLAIR $(B)$, precontrast T1-weighted $(C)$, postcontrast T7-weighted $(D)$ and SWI ( $E$ and $F$ ) obtained after CT demonstrate bilateral posterior infarctions (white arrows, $A$ ), edema in the posterior parieto-occipital regions (white arrows, $B$ ), and some contrast enhancement (hollow white arrow, D; compare with C). Selected SWI shows extensive blooming artifacts compatible with hemorrhages predominantly in the cortex (white arrows, $E$ and F). Findings are more pronounced on the right side.

the offending pathogen and resulting in numerous clinical manifestations known commonly as cytokine release syndrome. ${ }^{14-16}$ Classic laboratory findings of cytokine release syndrome include decreased T-cells and natural killer cells and, most important, an increase in interleukin 6, leading to clinical symptoms of fever and multiorgan dysfunction. This massive release of cytokines may damage and result in breakdown of the BBB and is a mechanism that may explain the development of PRES in our patients with COVID-19. Furthermore, hypoxia is a well-known trigger of inflammation, both at the local and systemic levels. ${ }^{17,18}$ Both of our patients had labile blood pressures, with the first patient rapidly fluctuating from significant hypotension to severe hypertension in a short time. This also is a commonly described risk factor for the development of PRES and may explain the neuroimaging findings. In addition, the COVID-19 virus, by means of the spike protein $\mathrm{S} 1$, has a high affinity for the human ACE2 receptors, which are expressed on numerous cells types, including the capillary endothelium. ${ }^{5,19-22}$ Current data suggest that engagement of the endothelium by the virus can cause damage to its lining and result in increased permeability of the BBB. This scenario can result in loss of homeostatic regulation of blood flow to the brain, increased susceptibility to blood pressure changes, and, as in our patients, brain edema. The presence of superimposed hemorrhages may be related to coagulopathy, which is also a sequela of cytokine release syndrome due to liver dysfunction and consumption of clotting factors as part of the disseminated intravascular coagulation cascade.

It is suspected that endothelial damage to the $\mathrm{BBB}$ precedes the actual invasion of the virus into the brain. Once the virus accesses the brain, it may also attack neurons, by virtue of the S1ACE2 interaction. This may be the prelude to severe parenchyma destruction seen in acute necrotizing encephalop-

and intraparenchymal hematomas, as was the case with our patients. PRES-related intracranial hemorrhage has been associated with poor patient outcome. ${ }^{10-12}$ In addition, abnormal contrast enhancement may also be seen in some patients with PRES as the parenchymal insult becomes subacute. Occasionally, patients may also develop cytotoxic edema, which is reflected by restricted diffusion on MR imaging, such as was seen in our patients. 9,13

COVID-19-infected critically ill patients have a massive inflammatory reaction that is proposed to be due to rapid accumulation of T-cells and macrophages, resulting in release of a large number of cytokines into the bloodstream aiming to destroy athy. ${ }^{3,4,23-25}$ In this context, can COVID-19-mediated PRES be considered a gateway to COVID-19-mediated a cute necrotizing encephalopathy? Although the pathogenesis of postinfectious acute necrotizing encephalopathy may be related to the same cytokine storm that has been described in patients with COVID-19 and may also be responsible for some cases of PRES, a link between both is still not well established. ${ }^{3,19,25}$ Acute necrotizing encephalopathy typically involves different brain regions, including the thalami, a finding not observed in our patients. ${ }^{4,23,24}$ Both of our patients recovered with medical management and did not develop more ominous brain lesions, in line with described favorable clinical outcomes of most cases of non-COVID-19 PRES. 


\section{CONCLUSIONS}

We presented 2 patients with COVID-19 who demonstrated imaging findings compatible with hemorrhagic PRES. Although multifactorial, PRES in hospitalized patients with COVID-19 may be explained by a combination of cytokine release syndrome and direct SARS-CoV-2-mediated breakdown of the BBB, rendering patients susceptible to developing PRES, particularly in the setting of labile blood pressure. Despite significant brain abnormalities, both patients survived and showed normal mental status following the resolution of COVID-19-associated symptoms. PRES may be a neurologic manifestation of COVID-19 infection.

\section{REFERENCES}

1. Coronavirus disease (COVID-19) Pandemic. Geneva: World Health Organization. 2020. https://www.who.int/emergencies/diseases/novelcoronavirus-2019. Accessed April 15, 2020

2. Jin Y, Cai L, Cheng Z, et al; for the Zhongnan Hospital of Wuhan University Novel Coronavirus Management and Research Team, Evidence-Based Medicine Chapter of China International Exchange and Promotive Association for Medical and Health Care (CPAM). A rapid advice guideline for the diagnosis and treatment of 2019 novel coronavirus (2019-nCoV) infected pneumonia (standard version). Mil Med Res 2020;7:4 CrossRef Medline

3. Filatov A, Sharma P, Hindi F, et al. Neurological complications of coronavirus (COVID-19): encephalopathy. Cureus 2020;12:e7352 CrossRef Medline

4. Poyiadji N, Shahin G, Noujaim D, et al. COVID-19-associated acute hemorrhagic necrotizing encephalopathy: CT and MRI features. Radiology 2020 Mar 31 [Epub ahead of print] CrossRef Medline

5. Mao L, Jin H, Wang M, et al. Neurologic manifestations of hospitalized patients with coronavirus disease 2019 in Wuhan, China. JAMA Neurol 2020 Apr 10 [Epub ahead of print] CrossRef Medline

6. National Health Commission of the People's Republic of China. Diagnosis and treatment of the novel coronavirus pneumonia. http://www.nhc.gov.cn/. Accessed April 15, 2020

7. Ding Y, He L, Zhang Q, et al. Organ distribution of severe acute respiratory syndrome (SARS) associated coronavirus (SARS-CoV) in SARS patients: implications for pathogenesis and virus transmission pathways. J Pathol 2004;203:622-30 CrossRef Medline

8. Arabi YM, Balkhy HH, Hayden FG, et al. Middle East Respiratory Syndrome. N Engl J Med 2017;376:584-94 CrossRef Medline

9. Bartynski WS, Boardman JF. Distinct imaging patterns and lesion distribution in posterior reversible encephalopathy syndrome. AJNR Am J Neuroradiol 2007;28:1320-27 CrossRef Medline

10. Hefzy HM, Bartynski WS, Boardman JF, et al. Hemorrhage in posterior reversible encephalopathy syndrome: imaging and clinical features. AJNR Am J Neuroradiol 2009;30:1371-79 CrossRef Medline
11. Sharma A, Whitesell RT, Moran KJ. Imaging pattern of intracranial hemorrhage in the setting of posterior reversible encephalopathy syndrome. Neuroradiology 2010;52:855-63 CrossRef Medline

12. Yamagami K, Maeda Y, Iihara K. Variant type of posterior reversible encephalopathy syndrome associated with deep brain hemorrhage: case report and review of the literature. World Neurosurg 2020;134:176-81 CrossRef Medline

13. Donmez FY, Basaran C, Kayahan Ulu EM, et al. MRI features of posterior reversible encephalopathy syndrome in 33 patients. $J$ Neuroimaging 2010;20:22-28 CrossRef Medline

14. Mehta P, McAuley DF, Brown M, et al. COVID-19: consider cytokine storm syndromes and immunosuppression. Lancet 2020;395:1033-34 CrossRef Medline

15. Wang $\mathrm{W}, \mathrm{He} \mathrm{J}$, Lie $\mathrm{P}$, et al. The definition and risks of cytokine release syndrome-like in 11 COVID-19-infected pneumonia critically ill patients: disease characteristics and retrospective analysis. MedRziv https://www.medrxiv.org/content/10.1101/2020.02.26.20026989v1. Accessed April 15, 2020

16. Xie J, Tong Z, Guan X, et al. Clinical characteristics of patients who died of coronavirus disease 2019 in China. JAMA Netw Open 2020;3:e205619 CrossRef Medline

17. Eltzschig HK, Carmeliet P. Hypoxia and inflammation. N Engl J Med 2011;364:656-65 CrossRef Medline

18. Bartels K, Grenz A, Eltzschig HK. Hypoxia and inflammation are two sides of the same coin. Proc Natl Acad Sci USA 2013;110:1835152 CrossRef Medline

19. Baig AM, Khaleeq A, Ali U, et al. Evidence of the COVID-19 virus targeting the CNS: tissue distribution, host-virus interaction, and proposed neurotropic mechanisms. ACS Chem Neurosci 2020;11:99598 CrossRef Medline

20. Netland J, Meyerholz DK, Moore S, et al. Severe acute respiratory syndrome coronavirus infection causes neuronal death in the absence of encephalitis in mice transgenic for human ACE2. J Virol 2008;82:7264-75 CrossRef Medline

21. Li YC, Bai WZ, Hashikawa T. The neuroinvasive potential of SARSCoV2 may play a role in the respiratory failure of COVID-19. J Med Virol 2020 Feb 27 [Epub ahead of print] CrossRef Medline

22. Wrapp D, Wang N, Corbett KS, et al. Cryo-EM structure of the 2019nCoV spike in the prefusion conformation. Science 2020;367:126063 CrossRef Medline

23. Wong AM, Simon EM, Zimmerman RA, et al. Acute necrotizing encephalopathy of childhood: correlation of MR findings and clinical outcome. AJNR Am J Neuroradiol 2006;27:1919-23 Medline

24. Abdelrahman HS, Safwat AM, Alsagheir MM. Acute necrotizing encephalopathy in an adult as a complication of H1N1 infection. BJR Case Rep 2019;5:20190028 CrossRef Medline

25. Wu X, Wu W, Pan W, et al. Acute necrotizing encephalopathy: an underrecognized clinicoradiologic disorder. Mediators Inflamm 2015;2015:792578 CrossRef Medline 